\title{
Small-bowel obstruction secondary to wireless capsule enteroscopy: extraction of the capsule without enterotomy
}

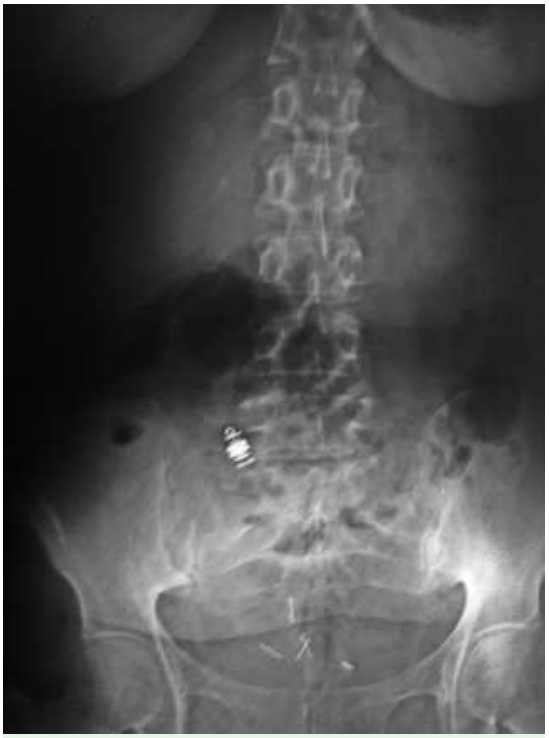

Fig. 1 Plain abdominal radiograph showing the capsule in the right lower quadrant of the abdomen.

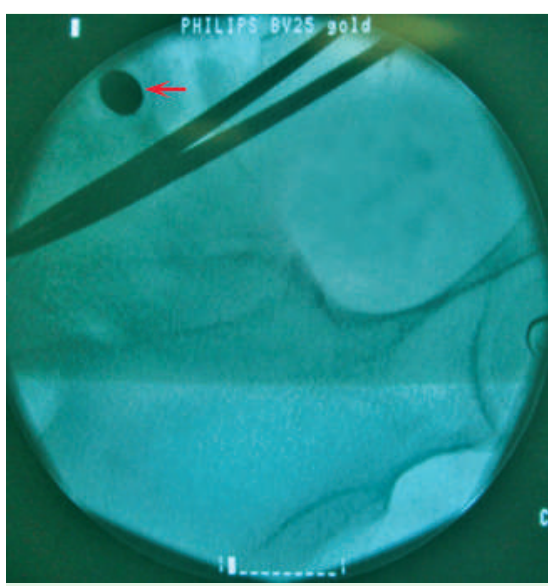

Fig. 2 Fluoroscopic view of the capsule.

Although wireless capsule enteroscopy is a relatively noninvasive diagnostic tool for exploring the whole small intestine endoscopically $[1,2]$, the contraindications and complications of this new technique have not yet been fully described.

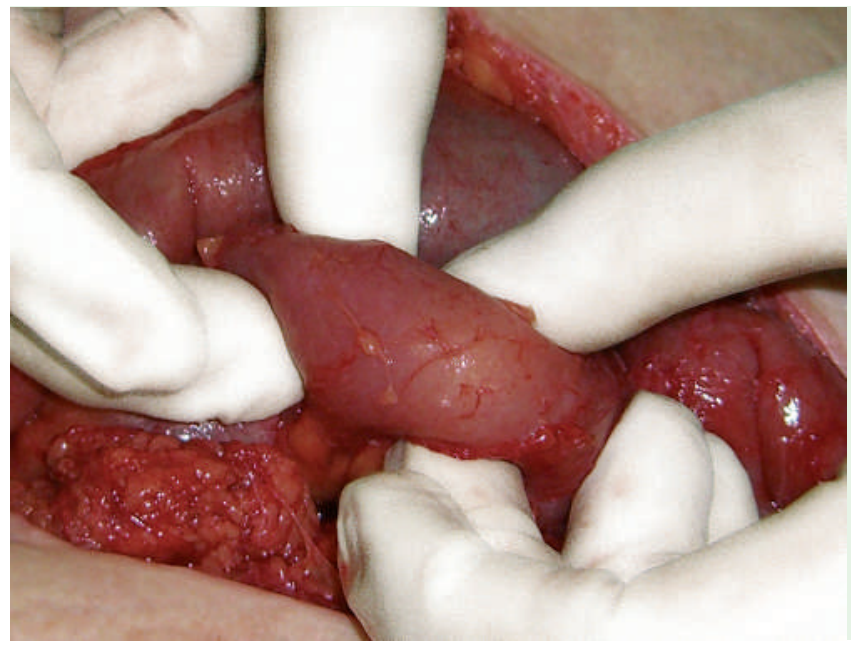

Fig. 3 At surgery the impacted wireless capsule was identified as the cause of the smallbowel obstruction.

A 46-year-old woman was admitted with a 3-month history of gastrointestinal bleeding of unknown origin. She had had a right hemicolectomy and terminal ileum resection because of severe gastrointestinal bleeding 10 years previously, when the histopathological diagnosis was Crohn's disease. No pathological findings were detected in a small-bowel series or on gastroscopic and colonoscopic examination, and so capsule enteroscopy was performed. Three days later she had to undergo surgery because she had developed signs of small-bowel obstruction. Plain abdominal radiography demonstrated the capsule in the right lower quadrant ( $\bullet$ Fig. 1), and the exact location of the capsule was determined by intraoperative fluoroscopy ( $\bullet$ Fig. 2 ). The adhesions that were causing capsule impaction and intestinal obstruction were dissected ( $\bullet$ Fig. 3 ). The capsule was swept through the colon to the rectum by manipulation and extracted by digital rectal examination peroperatively. The patient was discharged 3 days after surgery and she experienced no further problems.
To our knowledge, this is the first case of capsule extraction without enterotomy or intestinal resection in a patient who had a history of both previous abdominal surgery and Crohn's disease. The overall incidence of capsule retention is $0.75 \%$, but this figure reaches $21 \%$ in patients with known stenosis $[3,4]$. Fewer than $1 \%$ of patients with capsule retention require surgery [5]. Any procedure has both limitations and potential complications, and capsule enteroscopy is no exception. Before performing capsule enteroscopy in a patient who has risk factors for capsule retention or intestinal obstruction, the patient should be made fully aware of the potential need for surgery. Wireless capsule enteroscopy should not be performed in patients who are unwilling to undergo surgery or in patients who are unfit for surgery.

Endoscopy_UCTN_Code_CPL_1AI_2AB 
O. Irkorucu, O. Tascilar, A. U. Emre,

G. K. Cakmak, K. Karakaya, B. H. Ucan, M. Comert

Department of Surgery, Zonguldak Karaelmas University School of Medicine, Kozlu-Zonguldak, Turkey

\section{References}

1 Delvaux M, Gay G. Capsule endoscopy in 2005: facts and perspectives. Best Pract Res Clin Gastroenterol 2006; 20: 23-39

2 Eliakim R, Adler SN. Capsule endoscopy in Crohn's disease: the European experience. Gastrointest Endosc Clin N Am 2004; 14 129-137

3 de Franchis R, Avesani EC, Abbiati C et al. Unsuspected ileal stenosis causing obscure G bleeding in patients with previous abdominal surgery - diagnosis by capsule endoscopy: a report of two cases. Dig Liver Dis 2003; 35: 577-584

4 Cheifetz SA, Sachar D, Lewis B. Small bowel obstruction: indication or contraindication for capsule endoscopy? Gastrointest Endosc 2004; 59: AB461

5 Cave DR. Video capsule endoscopy. Clin Perspect Gastroenterol 2002; 5: 203 -207
Bibliography

DOI 10.1055/s-2007-966709

Endoscopy 2007; 39: E286-E287

(c) Georg Thieme Verlag KG Stuttgart · New York . ISSN 0013-726X

\section{Corresponding author}

\section{Comert, MD}

Department of Surgery

Zonguldak Karaelmas Universitesi Hastane Bashekimlgi

67600-Kozlu-Zonguldak

Turkey

Fax: +90-3722610155

mustafacomert@hotmail.com 